\title{
Development and characterization of perlite from Lamba, Albay, Bicol as packing material and the design of a packed column for the absorption of ammonia gas
}

\author{
Beatriz San Mateo ${ }^{1}$, Jervin Valorozo $^{2}$, Ma. Niña Jasmer Yturralde $^{1,3, *}$ and Lola Domnina Pestaño \\ ${ }^{1}$ Chemical Engineering Department, Faculty of Engineering, University of Santo Tomas \\ ${ }^{2}$ Research Center for the Natural and Applied Science, University of Santo Tomas, España Boulevard 1015, Manila, \\ The Philippines
}

\begin{abstract}
Gas absorption is a unit operation and separation process wherein soluble components of a gas mixture are dissolved in liquid solvent. This unit operation utilizes packing materials which play a vital role in providing surface area for gas and liquid contact. In this study, perlite from Lamba, Albay, Bicol was used in the production of packing material. The objectives of the study are to develop and characterize a packing material using a geopolymer derived from perlite and to design a packed column for the absorption of ammonia gas. The study determines the ideal perlite- $\mathrm{Na}_{2} \mathrm{SiO}_{3}$ concentration, packing factor, and $\mathrm{L} / \mathrm{D}$ ratio. Three perlite- $\mathrm{Na}_{2} \mathrm{SiO}_{3}$ concentrations $(45 \%, 60 \%, 75 \%$ wt. $\mathrm{Na}_{2} \mathrm{SiO}_{3}$ ) were subjected to various tests such as: thermal stability, chemical resistance, and compressive strength. The $45 \%$ wt. $\mathrm{Na}_{2} \mathrm{SiO}_{3}$ exhibited the least weight loss and the highest compressive strength making this geopolymerized perlite a potential packing material for gas absorption with a packing factor of $0.00175 \mathrm{ft}^{-1}$. Based on the results, a packed column was designed for the absorption of ammonia gas with an $\mathrm{L} / \mathrm{D}$ ratio of 2.5 .
\end{abstract}

\section{Introduction}

For refineries and other chemical industries, hazardous gas wastes are treated through the process of absorption [1]. Absorption refers to the disposition of hazardous gas pollutants from a stream where they are dissolved by a liquid.

Gas-liquid absorption is a heterogeneous process in which it involves the transfer of a soluble component of a gas phase into a relatively non-volatile liquid absorbent [2]. One of the most prevalent and rapidly developing means used to carry out the absorption process on an industrial scale is the packed column. A packed column is a piece of pipe set on its end and filled with an inert material, also known as packing materials [3]. In general, the packed tower operates in a countercurrent manner, wherein the liquid enters the system from the top and wets the surfaces of the packings, while the gas stream containing the effluent enters the bottom. As the two streams come in intimate contact with one another, the components of the effluent are absorbed into the liquid [4].

For a packed column, the packing section is responsible in providing the surface area where the liquid and gas contact upon making it an important part of the column.

Packing material helps obtain a larger heat transfer area between the two substances in contact and obtain the optimum absorption efficiency of the packed column [5].
Perlite is an amorphous volcanic glass that expands by a factor of 4-20 when rapidly heated to $1400-1800 !^{\circ} \mathrm{F}$ $\left(760-980^{\circ} \mathrm{C}\right)$. Chemically, crude perlite is a metastable amorphous silicate. Geopolymerization is an innovative technology that utilizes solid aluminosilicate and alkali metal silicate solutions to produce new materials characterized by three-dimensional polymeric structures called geopolymers or inorganic polymers (Davidovits, 2005). Perlite, however, has not been extensively studied as a potential aluminosilicate source for the synthesis of inorganic polymers through geopolymerization.

The primary aim of this research is to develop and characterize a packing material using a geopolymer derived from perlite from Lamba, Albay, Bicol and to design a packed column for the absorption of ammonia gas. In this study, the proponents aim to answer the following:

1. What is the most ideal perlite-sodium silicate ratio of the geopolymerized packings?

2. What is the packing factor of the product derived from the experiment?

3. What is the L/D of the gas absorber designed?

\footnotetext{
* Corresponding author: lbpestano@ust.edu.ph
} 


\section{Material and methods}

\subsection{Raw material collection and preparation}

Unexpanded perlite was obtained from Lamba, Legazpi City, Albay, Bicol through UBS Marketing Corporation. The chemicals and reagents were procured from the Laboratory Equipment and Supplies Office (LESO) of UST.

\subsection{The equipment used}

The laboratory equipment such as beakers, flasks, stirring rods, and funnels were borrowed from LESO. The analytical balance was available at the Material Science Laboratory of RCNAS and also the equipment to be used for the testing of the samples.

Fabrication of packed column and the silicon mold was done outside of the university.

\subsubsection{Fabrication of geopolymerized perlite packings}

\section{Geopolymerization of perlite}

Geopolymeric synthesis increases mechanical and physicochemical properties. Geopolymers exhibit high surface hardness, high mechanical strength, fire and chemical resistance, thermal stability, low density, and micro- or nanoporosity [7]. The perlite was mixed with sodium silicate into concentrations of $45 \%, 60 \%$ and $75 \%$ by mass of sodium silicate was prepared by weighing sodium silicate solution and perlite using the ratios [8].

\section{Curing of mixtures}

The mixtures were transferred to six cylindrical silicone molds. It was cured in open air for 24 hours before curing in a dry oven at $150 \mathrm{oC}$ for 24 hours [8]. A total of 27 samples were prepared and the resulting samples were cylindrical in shape with a height of $2 \mathrm{~cm}$ and a diameter of $6 \mathrm{~cm}$.

\subsubsection{Testing of geopolymerized perlite samples}

\section{Thermal stability}

A container was tared and the geopolymerized perlite sample was weighed. Both the geopolymerized perlite sample and container were placed into the thermogravimetric analyzer at ambient temperature. The geopolymerized perlite sample was heated at a constant rate of $10^{\circ} \mathrm{C}$ per minute under nitrogen gas. The thermogravimetry curve was recorded until the sample temperature reached $800^{\circ} \mathrm{C}$ [9].

\section{Chemical resistance}

The reagent used was $10 \%$ weight ammonium hydroxide solution. Each sample was measured of its weight before being totally immersed in fresh reagent for seven days in standard laboratory conditions. The ammonium hydroxide solution was stirred manually every 24 hours.

After the seven-day period, the geopolymerized perlite samples were removed from the solution and washed with running water to remove the basic solution. They were patted dry with a dry tissue paper and then immediately weighed, and their dimensions measured. The surface and appearance of the geopolymerized samples were observed after their exposure to the reagent (ASTM D 543-95).

\section{Compression strength}

The geopolymerized samples were placed in the universal testing machine with the load set at a rate of 20 to $50 \mathrm{psi} / \mathrm{s}$. The samples were loaded until failure and the ultimate load was recorded.

\subsubsection{Procurement and fabrication of gas absorber}

The packed column was fabricated by Polymer Products (Phil.), Inc. using chemical grade fiberglass. The frame was fabricated by Wellbilt Stainless Steel Corp. using stainless steel. The chemical grade tubes, pump, control valves, flow meter, and sump tank were obtained from hardware stores located in Binondo.

\subsubsection{Experimental set-up}

Figure 1 shows the diagram of the gas absorber with its properly labeled parts.

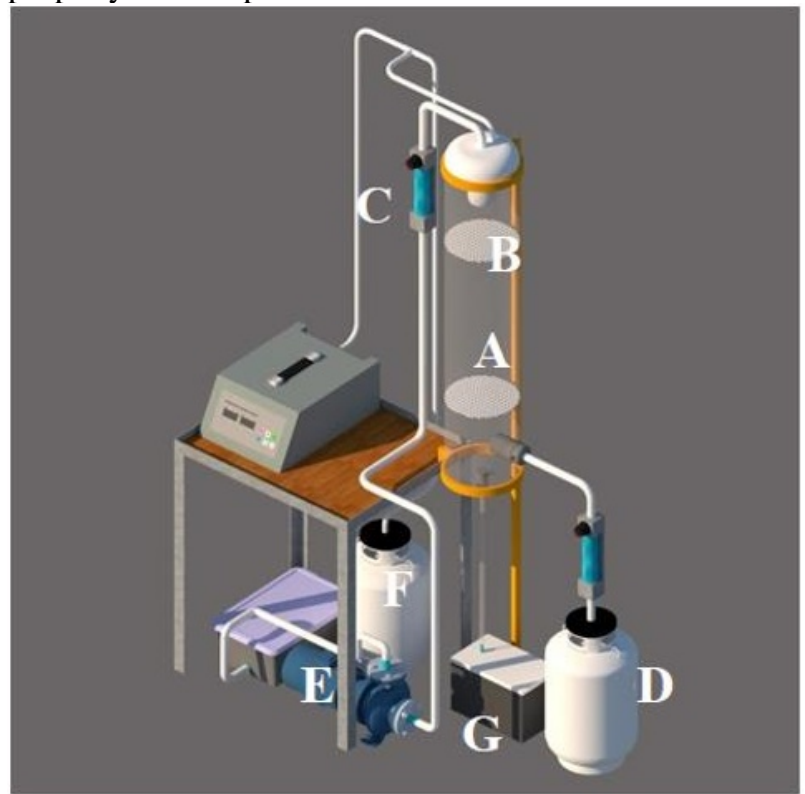

Figure 1. Diagram of a Gas Absorption Set-Up

Parts :
A. Packing Column
A pressure vessel that has a
B. Wire Mesh packed section.
Used to hold the packings.
C. Flow Meter
A device used to measure the quantity of water flowing into the column. 
D. Gas Cylinder
E. Pump

F. Distilled Water Tank

G. Sump Tank
Stores the ammonia gas.

A device that assists in moving the water from the source to the column.

Stores the distilled water to be used.

Stores the outflow of liquid from the column.

\subsubsection{Fabrication of packed column}

The metal mold to be used for the fabrication of the packed column was fabricated at Wellbilt Stainless Steel Corp. The mold is 1.2 meters in length and sixcentimeters in diameter and has flaps of two inches on both sides. The metal molds were forwarded to Polymer Products (PHIL.), Inc. who fabricated the packed column with chemical grade fiberglass.

\subsubsection{Assembly of packed column}

The gas absorber was assembled at the Unit Operations Laboratory, Roque Ruaño Building, University of Santo Tomas.

\subsubsection{Gas absorption experiment}

\section{Feedstock and operating conditions}

The gas feed was composed of ammonia whereas the liquid feed was composed of distilled water only. The operating conditions was done at room temperature and at atmospheric pressure.

\section{Trials}

There were three trials done for each $\mathrm{L} / \mathrm{G}$ ratio with fresh packings used for every trial. The L/D ratio was 2.5 and also remained constant throughout the trials. Each trial lasted for 30 minutes where in the pressure drop was recorded when the packed column has flooded using a Utube mercury manometer. A $20 \mathrm{~mL}$ sample was taken every five minutes for the determination of the collection efficiency. Table 1 shows the summary of L/G ratios used in the gas absorption experiment.

Table 1. $\mathrm{L} / \mathrm{G}$ ratio and the liquid and gas flow rates

\begin{tabular}{|c|c|c|}
\hline L/G & $\begin{array}{c}\text { Liquid Flow } \\
\text { Rate }(\mathrm{kg} / \mathrm{s})\end{array}$ & $\begin{array}{c}\text { Gas Flow } \\
\text { Rate }(\mathrm{kg} / \mathrm{s})\end{array}$ \\
\hline 0.023 & 0.033 & 1.47 \\
\hline 0.028 & 0.042 & 1.47 \\
\hline 0.034 & 0.05 & 1.47 \\
\hline
\end{tabular}

\subsubsection{Calculation of the Packing Factor (Fp)}

The packing factor was determined using the generalized

correlation for pressure drop in Figure 2. The packing factor can be found by solving the $\mathrm{Y}$-axis equation, Equation 1, for Fp [10].

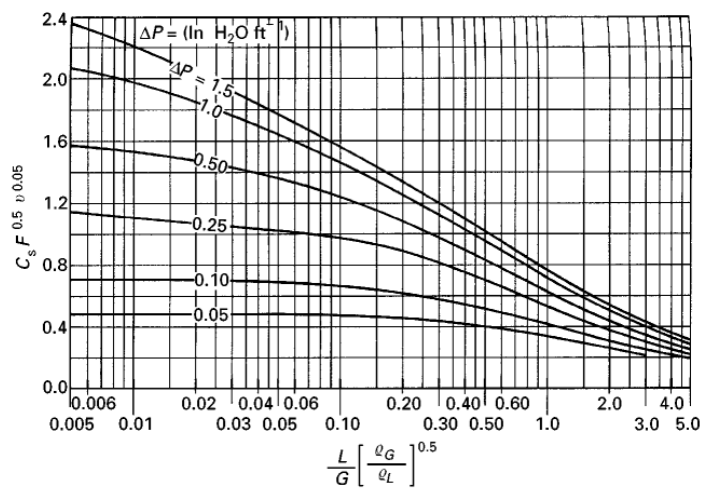

Figure 2. Generalized Pressure Drop Correlation (Eckert, 1994)

$\mathrm{CP}=\mathrm{CsFp} \mathrm{p}^{0.5} \mathrm{v}^{0.05}=\mathrm{Us}\left(\frac{\rho_{g}}{\rho_{1}-\rho_{g}}\right)^{0.5} \mathrm{Fp}^{0.5} \mathrm{v}^{0.05}$

\section{Solving for $F_{L G}$}

FLG is a dimensionless flow parameter which is the abscissa scale term in the generalized pressure drop correlation graph from Eckert modified by Strigle [10]. The flow parameter was solved by using Equation 2. Where in $\mathrm{L}$ and $\mathrm{G}$ are the liquid and gas flow rates and $\rho \mathrm{G}$ and $\rho \mathrm{L}$ are the densities of the gas and liquid.

$F_{L G}=\frac{L}{G}\left(\frac{\rho_{C}}{\rho_{L}}\right)^{0.5}$

\section{Determination of the pressure drop of the packed column}

The pressure drop of the packed column was measured using a U-tube mercury manometer in $\mathrm{mH} 2 \mathrm{O} / \mathrm{m}$ packing. The pressure drop was computed using Equation 3. The density of mercury $(\rho \mathrm{m})$ is $1354.6 \mathrm{~kg} / \mathrm{m}^{3}$, the acceleration constant (gc) as $9.8 \mathrm{~m} / \mathrm{s}^{2}$, and $\mathrm{h}(\mathrm{m})$ is the height difference.

$\Delta \mathrm{P}=\rho_{\mathrm{mg}} \mathrm{h}$

Plotting the pressure drop and $F_{L G}$

The resulting pressure drop and flow parameter was plotted in the generalized pressure drop correlation graph taken from Eckert modified by Strigle [10] shown in Figure 3 , in order to obtain the value of the ordinate.

\section{Solving for packing factor}

The ordinate, $\mathrm{CP}$, is obtained from the graph. It is known as the capacity parameter and is defined in Equation 1. The C-factor (Cs) was computed using Equation 4 and the kinematic viscosity of the liquid (v) was computed using Equation 5. 
After obtaining the needed values, the packing factor, Fp, was determined by using Equation 6.

$$
\begin{gathered}
C s=u\left[\frac{\rho_{g}}{\rho_{1}-\rho_{g}}\right]^{0.5} \\
v=\frac{\mu_{1}}{\rho_{1}} \\
F p={\frac{C p}{C s v^{0.005}}}^{2}
\end{gathered}
$$

\section{Results and discussion}

\subsection{Thermal stability}

The thermal stability of the geopolymerized perlite was tested using Thermogravimetric Analysis. The effect of subjecting the specimen to a high temperature to the sample mass was investigated in which the weight the of specimen was observed throughout the testing process. Figure 3 shows the effect of constant increase in temperature of $10^{\circ} \mathrm{C} / \mathrm{min}$ percent against the weight of the sample.

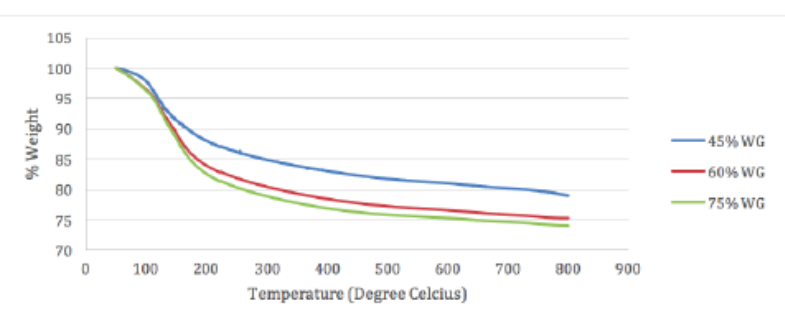

Figure 3. Effect of temperature to percent weight loss

It is shown in the graph that the weight decreases as the temperature increases. A sharp decrease in weight between $100^{\circ} \mathrm{C}$ and $200^{\circ} \mathrm{C}$ is attributed to the loss of evaporable water in the geopolymer. After the rapid decline, the rate of weight loss stabilized between $150^{\circ} \mathrm{C}$ and $800^{\circ} \mathrm{C}$ with a retained weight $\%$ of $79.5 \%, 75.5 \%$ and $74 \%$ for $45 \%, 60 \%$ and $75 \%$ WG, respectively. Similar results were observed from the study of Bakria [11] in which the geopolymer peaked at $127^{\circ} \mathrm{C}$.

\subsection{Chemical resistance}

The test for the chemical resistance of the geopolymerized sample used was ASTM D 543-9. It tests the effect of chemical reagents on the properties of specimen before and after immersion in the reagent. Figure 4 shows the effect of immersing the geopolymerized samples in ten percent weight ammonium hydroxide solution for seven days.

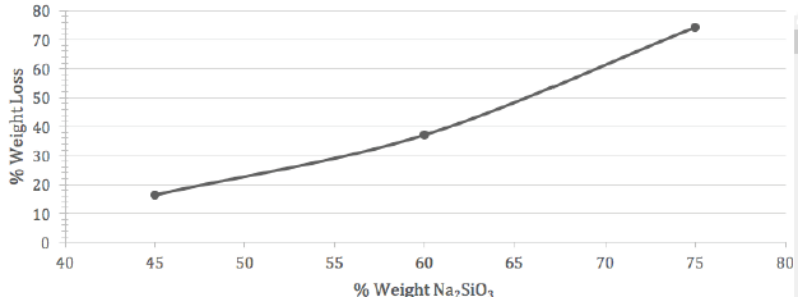

Figure 4. Effect of ammonium hydroxide to weight loss

It is shown in the graph that as the weight percent concentration of $\mathrm{Na} 2 \mathrm{SiO} 3$ increases, the percentage weight loss also increases. This was also observed in the study by Erdogan [8], where perlite geopolymer mortars were submerged in $10 \% \mathrm{H} 2 \mathrm{SO} 4$ solution. It was observed that sodium-silicate activated specimens are more resistant to acidic conditions than basic conditions.

\subsection{Compression strength}

A universal testing machine was used to determine the compressive strength of the geopolymerized samples since they are to be dumped in the packed column. Figure 6 shows how the different ratios of $\mathrm{Na}_{2} \mathrm{SiO}_{3}$ to perlite affect the compressive strength of the geopolymerized sample.

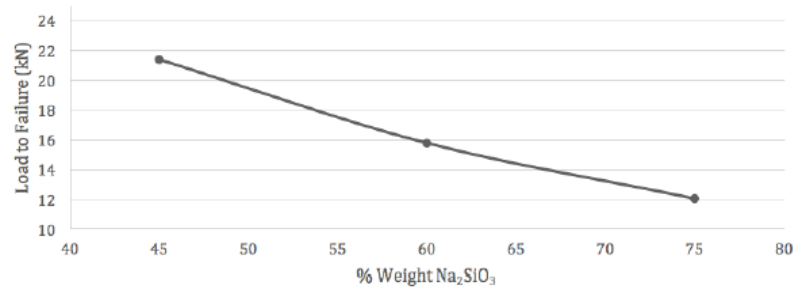

Figure 5. Effect of $\mathrm{Na}_{2} \mathrm{SiO}_{3}$ to perlite ratio to compression strength

It can be seen in the figure that as the weight percent of $\mathrm{Na}_{2} \mathrm{SiO}_{3}$ increases in the geopolymerized sample, the compressive strength of the geopolymerized sample decreases. The ratio that exhibited the highest compressive strength was the $45 \%$ weight $\mathrm{Na}_{2} \mathrm{SiO}_{3}$ mixture wherein the load to failure of the sample was at $21.40 \mathrm{kN}$ whereas the $75 \%$ weight $\mathrm{Na}_{2} \mathrm{SiO}_{3}$ mixture's load to failure was only at $12.09 \mathrm{kN}$. According to Erdogan [8], a linear increase is observed with an increase in the amount added of sodium silicate.

\subsection{Selection of the best $\mathrm{Na}_{2} \mathrm{SiO}_{3}$ to perlite ratio}

Based from the results of the previous tests, the best $\mathrm{Na}_{2} \mathrm{SiO}_{3}$ to perlite ratio out of the three was the $45 \%$ weight $\mathrm{Na}_{2} \mathrm{SiO}_{3}$ ratio. It showed the least weight loss when subjected thermogravimetric analysis and to the chemical resistance test, and the highest compressive strength compared to the others. This $\mathrm{Na}_{2} \mathrm{SiO}_{3}$ to perlite ratio was used in the production of packings to be used for the absorption experiment. 


\subsection{Packing factor}

The packing factor (Fp) was solved using the pressure drop data collected from the absorption experiment at different liquid flow rates. The density of the gas $(\rho g)$ is $0.68 \mathrm{~kg} / \mathrm{m} 3$ which was solved using the ideal gas equation. The capacity parameter (CP) was extrapolated from the graph which resulted to an average packing factor $(\mathrm{Fp})$ of $0.00175 \mathrm{ft}-1$. The produced packings have a length of 10 $\mathrm{mm}$ and a diameter of $10 \mathrm{~mm}$.

\subsection{Area $\left(\mathrm{m}^{2} / \mathrm{m}^{3}\right)$}

The area $\left(\mathrm{m}^{2} / \mathrm{m}^{3}\right)$ of the packings was computed by solving for the surface area of the packings using Equation 7 and solving for the volume of the packings using Equation 8. After obtaining the values, the surface area was divided by the volume to compute for the area. The computed area of our perlite packings is $600 \mathrm{~m}^{2} / \mathrm{m}^{3}$.

$A=2 \pi r h+2 \pi r^{2}$

$\mathrm{V}=\pi \mathrm{r}^{2} \mathrm{~h}$

\subsection{Comparative analysis of random ceramic Raschig packings}

Table 2 shows the characteristics of random packings, namely raschig rings and the developed perlite cylinders. Comparing the perlite cylinders to the commercially available raschig rings, it can be observed that the perlited cylinders have a higher area and a significantly lower packing factor.

Table 2. Characteristics of Random Packings

\begin{tabular}{|c|c|c|}
\hline Name & Area $\left(\mathrm{m}^{2} / \mathrm{m}^{3}\right)$ & $\mathrm{F}_{\mathrm{p}}\left(\mathrm{m}^{-1}\right)$ \\
\hline \multirow{3}{*}{ Raschig rings } & 220 & 350 \\
\cline { 2 - 3 } & 164 & 180 \\
\cline { 2 - 3 } & 121 & 142 \\
\cline { 2 - 3 } & 82 & 85 \\
\hline Perlite cylinders & 600 & 0.00574 \\
\hline
\end{tabular}

\subsection{Packed column design}

Based from the packing factor taken from the experimental procedure, a packed column was designed for the large-scale application of the absorption of ammonia gas. The packed column would have a gas flow rates of 9800 LPM. The density and viscosity of the liquid would be $995.67 \mathrm{~kg} / \mathrm{m}^{3}$ and $0.8 \mathrm{cP}$, respectively whereas the gas density is $1.53 \mathrm{~kg} / \mathrm{m}^{3}$ taken from the Perry's Chemical Engineering Handbook, 8th ed. The packed column will have a recovery of $85 \%$ and an inlet gas of $30 \%$ mole ammonia and solvent of pure distilled water. The conditions were taken from the study of Zuehlsdorff [12].

\subsubsection{Material of construction}

The tower shell and heads are usually constructed using carbon steel. Since the packed column will be handling ammonia, which is a corrosive material, the material of construction for the packed column will be stainless steel 316 which is more resistant to corrosion compared to other stainless-steel grades.

\subsubsection{Operating temperature and pressure}

The operating temperature is at ambient temperature of 0 ${ }^{\circ} \mathrm{C}$ and the operating pressure is at a pressure of $1.5 \mathrm{~atm}$.

\subsubsection{Tower diameter}

The tower diameter was computed by first plotting the abscissa on the general pressure drop correlation graph found in Figure 3 to get the capacity parameter. From the equation of $\mathrm{CP}$ found in Equation 1, the superficial velocity was obtained (Us). The gas mass velocity at flooding $\left(\mathrm{GF}_{\mathrm{F}}\right)$ was solved using Equation 9 and the gas mass velocity $\left(\mathrm{G}_{\mathrm{v}}\right)$ using Equation 10 . After obtaining these values, the tower area, using Equation 11, was computed to be $0.0014 \mathrm{~m} 2$; thus the tower diameter was computed using Equation 12 is $0.042 \mathrm{~m}$.

$$
\begin{aligned}
& \mathrm{G}_{\mathrm{F}}=\mathrm{U}_{\mathrm{s}} \rho_{\mathrm{g}} \\
& \mathrm{G}_{\mathrm{v}}=0.62 \mathrm{G}_{\mathrm{F}} \\
& \mathrm{S}=\frac{\mathrm{G}}{\mathrm{G}_{\mathrm{F}}}
\end{aligned}
$$

Area $=\frac{\pi}{4} \mathrm{D}^{2}$

\subsubsection{Number of heat transfer units (NoG)}

The mole fraction of the exit gas ( $\left.\mathrm{y}_{2}\right)$ was 0.06 as stated from the study of Zuehlsdorff [12], thus the computed solute free mole fraction of the liquid from the mass balance equation, is 0.064 . Using the Equation 13, the Wiegand Equation, the number of heat transfer units computed was 0.2 .

$$
\mathrm{N}_{\mathrm{OG}}=0.5 \ln \left[\frac{1-\mathrm{y}_{2}}{1-\mathrm{y}_{1}}\right]+\int \frac{\mathrm{dy}}{\mathrm{y}-\mathrm{y}^{*}}
$$

\subsubsection{Height of heat transfer unit ( $\left.H_{O G}\right)$}

The Kga value was computed using Equation 14 and was found to have a value of $22.04 \mathrm{~kg}$-mol/s-m2-atm. To get $\mathrm{Kya}$, the value of Kga was multiplied to the pressure of the system, thus Kya is equal to $33.05 \mathrm{~kg}-\mathrm{mol} / \mathrm{s}-\mathrm{m} 2$. Having known these, the height of the heat transfer unit, $\mathrm{H}_{\mathrm{og}}$, was solved using Equation 15 and is equal to $5.4 \mathrm{~m}$.

$$
\mathrm{K}_{\mathrm{G}}=2.0+0.91 \mathrm{E}_{\mathrm{G}}^{2 / 3}
$$




$$
\mathrm{H}_{\mathrm{OG}}=\frac{\mathrm{v},}{\mathrm{Kya} \mathrm{S}}
$$

\subsubsection{Packing height (Z)}

The packing height, Z, was solved using Equation 16 and is equal to $1.06 \mathrm{~m}$.

$$
\mathrm{Z}=\left(\mathrm{H}_{\mathrm{OG}}\right)\left(\mathrm{N}_{\mathrm{OG}}\right)
$$

\subsubsection{Specification sheet}

\begin{tabular}{|c|c|c|c|}
\hline \multicolumn{4}{|c|}{ I. Design Parameters } \\
\hline \multicolumn{2}{|c|}{ Design Pressure (kPa) } & \multicolumn{2}{|l|}{167.19} \\
\hline \multicolumn{2}{|c|}{ Design Temperature $\left({ }^{\circ} \mathrm{F}\right)$} & \multicolumn{2}{|l|}{136} \\
\hline \multicolumn{4}{|c|}{ II. Physical, Chemical, and Transport Properties } \\
\hline Fluid & $\begin{array}{c}\text { Flow } \\
\text { Rate } \\
(\mathrm{kg} / \mathrm{hr})\end{array}$ & $\begin{array}{l}\text { Density } \\
\left(\mathrm{kg} / \mathrm{m}^{3}\right)\end{array}$ & $\begin{array}{l}\text { Viscosity } \\
\text { (Pa-s) }\end{array}$ \\
\hline Water & 878.05 & 995.67 & 0.0008 \\
\hline Ammonia Gas & 901.01 & 0.68 & $1.03 \times 10^{-5}$ \\
\hline \multicolumn{4}{|c|}{ III. Shell Dimensions } \\
\hline $\begin{array}{l}\text { Material of } \\
\text { Construction }\end{array}$ & \multicolumn{3}{|c|}{ Stainless Steel 316} \\
\hline Orientation & \multicolumn{3}{|c|}{ Vertical Cylindrical Shell } \\
\hline Diameter & \multicolumn{3}{|l|}{$0.042 \mathrm{~m}$} \\
\hline Packing Height & \multicolumn{3}{|l|}{$1.06 \mathrm{~m}$} \\
\hline Tower Height & \multicolumn{3}{|l|}{$1.25 \mathrm{~m}$} \\
\hline Shell Thickness & \multicolumn{3}{|c|}{$8.975 \mathrm{~mm}$} \\
\hline Head Thickness & \multicolumn{3}{|c|}{$8.975 \mathrm{~mm}$} \\
\hline Head Extension & \multicolumn{3}{|l|}{$0.021 \mathrm{~m}$} \\
\hline \multicolumn{4}{|c|}{ IV. Packing Material } \\
\hline Type & \multicolumn{3}{|c|}{ Perlite Cylinders } \\
\hline Packing Factor & \multicolumn{3}{|c|}{$0.00175 \mathrm{ft}^{-1}$} \\
\hline \multicolumn{4}{|l|}{ V. Internals } \\
\hline Support Plate & \multicolumn{3}{|c|}{$\begin{array}{l}\text { Model } 804 \text { Random Packing } \\
\text { Gas Injection Support Plate }\end{array}$} \\
\hline
\end{tabular}

Table 3. Specification Sheet of the Designed Gas Absorber

\subsubsection{Diagram of equipment}

The schematic diagram of the designed packed column is shown in Figure 6.

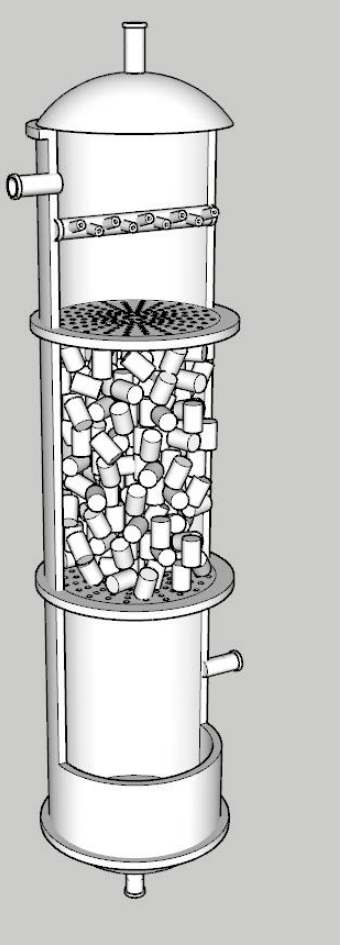

Figure 6. Schematic Diagram of the designed packed column

\section{Conclusion}

Perlite has the potential to be a packing material in gas absorption. A perlite geopolymer packing was developed with $45 \%$ by wt. $\mathrm{Na} 2 \mathrm{SiO} 3$ ratio of the geopolymerized packings and a packing factor, $\mathrm{Fp}$, of $0.000175 \mathrm{ft}^{-1}$. A packed column was designed for the absorption of ammonia gas with an $\mathrm{L} / \mathrm{D}$ ratio of 2.5

The authors would like to express their deepest gratitude to UBS Marketing for providing the raw material, unexpanded perlite, used in our research, to Welbilt Steel Corporation for the help in fabricate our packed column and its components, to Polymer Products (PHIL) Inc. for fabricating the column, and to the Research Center for the Natural and Applied Sciences at the Thomas Aquinas Research Complex for where experimentation, tests, and trials were conducted.

\section{References}

[1] McCabe, W. L., Smith, J. C. \& Harriott, P. (2005). Unit Operations of Chemical Engineering (7th ed.). In (E. D. Glandt, M. T. Klein \& T. F. Edgar, Eds.). USA: Mc-Graw Hill. Date Retrieved: February 27, 2018)

[2] Franks, R.G.E. 1967. Mathematical modeling in chemical engineering. John Wiley and Sons, Inc., New York, NY, USA, pp. 4-6.

[3] Cussler, E. L. (1997). Absorption. Diffusion: Mass Transfer in Fluid Systems (2nd ed. pp. 245264). USA: Cambridge University Press. Date Retrieved: February 28, 2018. 
[4] Jackson, Y.Z. (April 24, 2008). Modeling Gas Absorption. Worcester Polytechnic Institute. Worcester, USA. htps://web.wpi.edu/Pubs/Eproject/Available/E-project-042408-

33605/unrestricted/Modeling_Absorption.pdf.

Date Retrieved: February 28, 2018.

[5] Manyele, S.V. (April 15, 2008). Toxic acid gas absorber design consideration for air pollution control in process industries. Salaam, Tanzania. Date Retrieved: September 12, 2017.

[6] Tsaousi, G.M., et. Al (April 9, 2016). Characterization of the properties of perlite geopolymer pastes. Athens, Greece. Date Retrieved: March 4, 2018.

[7] Barbosa, $\quad$ V.F.F.; MacKenzie, K.J.D.;Thaumatutgo, C. (2000) Synthesis and characterization of materials based on inorganic polymers of alumina and silica: sodium polysialate polymers. Int. J. Inorg. Mater. 2 [4], 309-317. http:// dx.doi.org/10.1016/S14666049(00)00041-6. Date Retrieved: March 4, 2018.E

[8] Erdogan, S. T. (2011, September). Use of Perlite to Produce Geopolymers. Retrieved April, 2018, from

https://www.researchgate.net/profile/Sinan_Erd ogan/publication/274386335_Use_of_Perlite_to _Produce_Geopolymers/links/551e4ee40cf2a2d 9e13ba23b.pdf

[9] Kabra, S., et. AL (September 2013). International Journal of Innovative Research in Science, Engineering and Technology: Characterization and Study of Turkish Perlite. Kota, Rajasthan, India. Date Retrieved: March 2, 2018.

[10] Strigle, R. F., Jr. (1994). Packed Tower Design and Applications (2nd ed.). Houston, Texas: Gulf Publishing Company.

[11]Bakria, M., Kamarudin, H., BinHussain, M., Khairul Nizar, I., Zarina, Y., \& Rafiza, A. (2011). The effect of curing temperature on physical and chemical properties of geopolymers. Retrieved May, 2018, from https://ac.els-cdn.com/S1875389211006997/1s2.0-S1875389211006997-

main.pdf?_tid=b730ac1e -7edc-470c-be2b9efcdd439ecb\&acdnat $=15337443$ 25_0159d6ddeab248faf933ce4d97bb084

[12]Zuehlsdorff, D. (1979, April). Absorption of Ammonia in Water Using a Multiple Stage Crosscurrent Packed Column. Retrieved May, 2018, from https://www.google.com/url?sa=t\&rct=j\&q=\&e src $=$ s\&source $=$ web $\& c d=1 \& v e d=2$ ahUKEwiqoz B6t3cAhUIZt4KHSVFDEUQFjAAegQICBAC \&url=https://ir.library.oregonstate.edu/downloa ds/v405sd008\&usg=AOvVaw2n-

_mgCQOCs0fniPJlakx1 